OPEN ACCESS

Check for updates

\section{Estimated population wide benefits and risks in China of lowering sodium through potassium enriched salt substitution: modelling study}

\author{
Matti Marklund, ${ }^{1,2}$ Gitanjali Singh, ${ }^{2}$ Raquel Greer, ${ }^{3}$ Frederick Cudhea, ${ }^{2}$ Kunihiro Matsushita, ${ }^{3}$ \\ Renata Micha, ${ }^{2}$ Tammy Brady, ${ }^{4}$ Di Zhao, ${ }^{3}$ Liping Huang, ${ }^{1}$ Maoyi Tian, ${ }^{1,5}$ Laura Cobb, ${ }^{6}$ \\ Bruce Neal, ${ }^{1,7}$ Lawrence J Appel, ${ }^{3,4}$ Dariush Mozaffarian, ${ }^{2}$ Jason $\mathrm{H}$ Y Wu ${ }^{1}$
}

For numbered affiliations see end of the article.

Correspondence to:M Marklund mmarklund@georgeinstitute.org.au (or https://twitter.com/

MarklundMatti on Twitter: ORCID 0000-0002-3320-796X) Additional material is published online only. To view please visit the journal online.

Cite this as: $B M / 2020 ; 369: m 824$ http://dx.doi.org/10.1136 bmj.m824 Accepted: 24 February 2020

\section{ABSTRACT}

OBJECTIVES

To estimate the effects of nationwide replacement of discretionary salt (used at table or during cooking) with potassium enriched salt substitute on morbidity and death from cardiovascular disease in China.

DESIGN

Modelling study.

SETTING

China.

POPULATION

Adult population in China, and specifically individuals with chronic kidney disease (about 17 million people).

\section{INTERVENTIONS} estimate the effects of a nationwide intervention to replace discretionary dietary salt with potassium enriched salt substitutes (20-30\% potassium chloride). The models incorporated existing data and corresponding uncertainties from randomised trials, the China National Survey of Chronic Kidney Disease, the Global Burden of Disease Study, and the Chronic Kidney Disease Prognosis Consortium.

MAIN OUTCOME MEASURES

Averted deaths from cardiovascular disease, nonfatal events, and disability adjusted life years
Comparative risk assessment models were used to

\section{WHAT IS ALREADY KNOWN ON THIS TOPIC}

Replacement of dietary salt with potassium enriched salt substitutes is a promising strategy to reduce blood pressure and prevent cardiovascular disease in China and in other countries where consumption of sodium is high, potassium intake is low, and where the principal source of salt is discretionary

Relative benefits versus harms, in particular the risk of hyperkalaemia and cardiac deaths in individuals with advanced chronic kidney disease, are not established, limiting widespread implementation

\section{WHAT THIS STUDY ADDS}

A comparative risk assessment framework, incorporating potential benefits and harms, estimated that replacement of discretionary salt with potassium enriched salt substitutes could prevent nearly 500000 deaths from cardiovascular disease annually by reducing blood pressure

The increased consumption of potassium could lead to around 10000 additional deaths related to hyperkalaemia annually in individuals with chronic kidney disease but substantial net benefits would occur in these individuals

Quantitative estimates suggest that nationwide replacement of discretionary salt with potassium enriched salt substitutes could result in large net cardiovascular benefits in China, in the general population and in individuals with chronic kidney disease from a reduction in blood pressure were estimated after implementation of potassium enriched salt substitution. In individuals with chronic kidney disease, additional deaths from cardiovascular disease related to hyperkalaemia from increased intake of potassium were calculated. The net effects on deaths from cardiovascular disease were estimated as the difference and ratio of averted and additional deaths from cardiovascular disease.

\section{RESULTS}

Nationwide implementation of potassium enriched salt substitution could prevent about 461000 (95\% uncertainty interval 196339 to 704 438) deaths annually from cardiovascular disease, corresponding to $11.0 \%$ (4.7\% to $16.8 \%)$ of annual deaths from cardiovascular disease in China; 743000 (305803 to 1273098 ) non-fatal cardiovascular events annually; and 7.9 (3.3 to 12.9) million disability adjusted life years related to cardiovascular disease annually. The intervention could potentially produce an estimated 11000 (6422 to 16562) additional deaths related to hyperkalaemia in individuals with chronic kidney disease. The net effect would be about 450000 (183699 to 697 084) fewer deaths annually from cardiovascular disease in the overall population and 21000 (1928 to 42926) fewer deaths in individuals with chronic kidney disease. In deterministic sensitivity analyses, with changes to key model inputs and assumptions, net benefits were consistent in the total population and in individuals with chronic kidney disease, with averted deaths outweighing additional deaths.

Nationwide potassium enriched salt substitution in China was estimated to result in a substantial net benefit, preventing around one in nine deaths from cardiovascular disease overall. Taking account of the risks of hyperkalaemia, a substantial net benefit was also estimated for individuals with chronic kidney disease.

\section{Introduction}

In China, sodium intake is high (mean $4.1 \mathrm{~g} /$ day, more than double the limit recommended by the World Health Organization), ${ }^{1}$ and nearly half $(45 \%)$ of the Chinese population aged 35-75 have hypertension. ${ }^{2}$ In 2015, the annual number of deaths related to elevated systolic blood pressure was estimated at 2.3 million in China, an increase of $89 \%$ from $1990 .{ }^{3}$ High intake of sodium ( $>2 \mathrm{~g} /$ day) is believed to cause more than one in

\section{CONCLUSIONS}


seven of deaths from cardiovascular disease in China, and almost $30 \%$ of fatal strokes in those younger than 70 years are attributable to high consumption of sodium. ${ }^{4}$

The largest contributor to dietary sodium in Chinese homes is discretionary salt (that is, salt used at table or during cooking), contributing to about $70 \%$ of sodium intake in the 2015 China Health and Nutrition Survey. ${ }^{1}$ Hence a promising strategy to reduce dietary consumption of sodium is to replace dietary salt (sodium chloride) with lower sodium salt substitutes, where sodium chloride is partially replaced with nonsodium alternatives. These salt substitutes typically use potassium chloride as the main replacement, with smaller amounts of taste enhancers. Salt substitutes are available for standard table salt and other key sources of sodium, such as soy sauce. In meta-analyses of randomised controlled trials, potassium enriched salt substitutes (25-67\% potassium chloride), compared with standard salt (100\% sodium chloride), reduced average systolic blood pressure by $5 \mathrm{~mm} \mathrm{Hg}$ and diastolic blood pressure by $2 \mathrm{~mm} \mathrm{Hg} .{ }^{56}$ Potassium enriched salt substitutes were associated with a lower risk of death from cardiovascular disease in a cluster randomised trial in older Taiwanese adults. ${ }^{7}$ These findings have generated interest in the use of potassium enriched salt substitutes as a public health intervention to reduce diseases related to high blood pressure. The overall potential effect of potassium enriched salt substitutes to replace discretionary dietary salt in China, however, has not been quantified.

Concerns have been raised that potassium enriched salt substitutes might increase the risk of clinically important hyperkalaemia in individuals with advanced chronic kidney disease, increasing the risk of sudden cardiac death. ${ }^{8}$ Individuals with chronic kidney disease are advised to limit dietary potassium and avoid potassium enriched salt substitutes. ${ }^{9}$ In China, where most people with advanced chronic kidney disease are unaware of their condition, ${ }^{10}$ the risk of hyperkalaemia from a population based salt substitution is particularly relevant.

We modelled the effects of a national intervention to replace discretionary dietary salt with potassium enriched salt substitutes on morbidity and death from cardiovascular disease in China. The evaluation was designed to account for the benefits of lowering systolic blood pressure (and downstream diseases) and the potential consequences of hyperkalaemia.

\section{Methods}

Study design

We used comparative risk assessment models to estimate the overall effect of a nationwide intervention of potassium enriched salt substitution on the cardiovascular disease burden in China (fig 1). The model for estimating the benefits of this intervention was based on the blood pressure lowering effect of potassium enriched salt substitutes compared with standard salt, with results stratified by age and sex (referred to here as the blood pressure model). A separate model for estimating harms related to salt substitute use was based on the anticipated change in serum concentrations of potassium in individuals with chronic kidney disease (defined as an estimated glomerular filtration rate $<60 \mathrm{~mL} / \mathrm{min} / 1.73 \mathrm{~m}^{2}$, relating to chronic kidney disease stages $\geq \mathrm{G} 3 \mathrm{a}$ ), stratified by chronic kidney disease stage (referred to here as the potassium model). The net effect of the intervention, including benefits and harms, was estimated in the total population and specifically in those with chronic kidney disease.

\section{Intervention}

The modelled policy was a nationwide salt substitution intervention based on the Salt Substitute and Stroke Study, a large scale, cluster randomised controlled trial currently being conducted in 600 villages across five provinces in rural areas of northern China (clinicalTrials.gov NCT02092090) to estimate the effect of salt substitutes on risk of stroke. ${ }^{1112}$ The salt substitute used in the Salt Substitute and Stroke Study, manufactured according to national manufacturing standards (which requires $70 \pm 10 \%$ sodium chloride and $30 \pm 10 \%$ potassium chloride), was purchased from a local provider in each county. Sufficient amounts of potassium enriched salt substitutes (average 25\% potassium chloride) were distributed quarterly, free of charge, to cover household cooking and food preservation (average $20 \mathrm{~g} /$ day for each person). Monitoring was done at the time of distribution to confirm that the quantity of salt substitute provided was adequate to replace typical salt use by the household. Participants were given oral, written, and other reminders (eg, on cooking aprons) to reinforce use of the salt substitute. ${ }^{12}$ Participants were also advised to use the salt substitute more sparingly, and not more often, than previous use of dietary salt. This pragmatic trial provides a real world approximation of the overall intensity, coverage, compliance, and effects on systolic blood pressure of a potassium enriched salt substitute intervention in China.

\section{Data sources}

Blood pressure model (potential benefits)

Table 1 and eTables 1-5 present model inputs and assumptions. We used the 2015 age and sex specific estimates of mean systolic blood pressure (eTable 1) and outcomes for cardiovascular disease and chronic kidney disease for China from the Global Burden of Disease Study. ${ }^{313-15}$ Cardiovascular disease outcomes included death, non-fatal cardiovascular events, and disability adjusted life years (defined as the sum of years lost as a result of premature death and years lived with disability) related to cardiovascular disease, overall and for each cardiovascular disease subtype, including ischaemic heart disease, stroke (ischaemic and haemorrhagic), and other cardiovascular diseases. Based on age and sex specific systolic blood pressure distributions estimated in more than 500000 Chinese adults, ${ }^{16}$ we assumed that the standard deviation of systolic blood pressure in each age-sex group was 


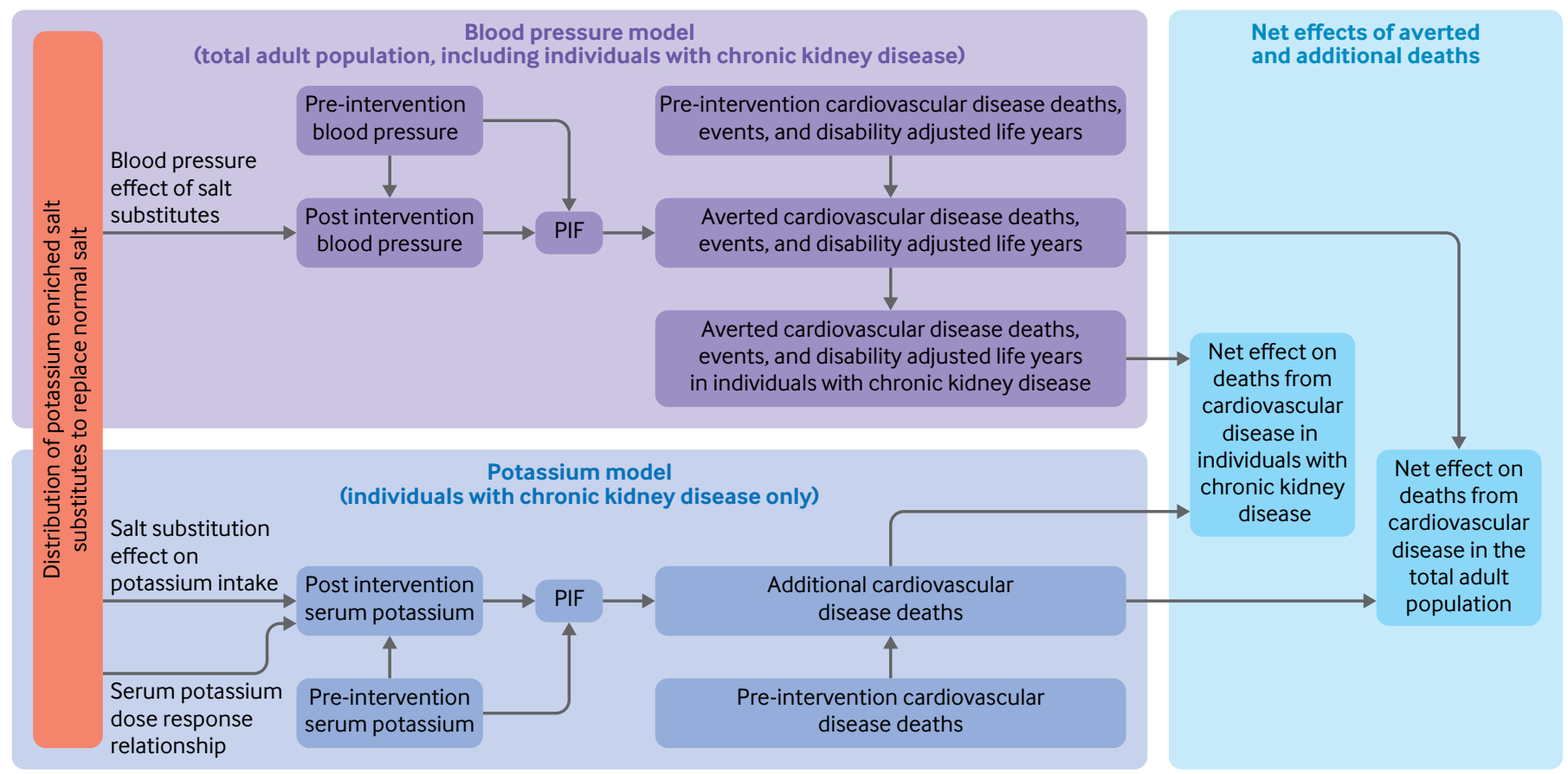

Fig 1 | Conceptual models used to estimate benefits, harms, and net effects of replacing dietary salt (sodium chloride) with potassium enriched salt substitutes. Distribution of potassium enriched salt substitutes to replace dietary salt was expected to reduce blood pressure in the adult population, with greater effects at older ages. In 24 age-sex groups, blood pressure distribution before the intervention and the lower blood pressure distribution after the intervention (that is, after replacement) were used to calculate a potential impact fraction (PIF), with risk estimates for blood pressure on outcomes of cardiovascular disease, for each of 11 subtypes of cardiovascular disease. The age, sex, and subtype specific PIF was multiplied by the pre-intervention estimates of the same groups for deaths from cardiovascular disease, non-fatal events, or disability adjusted life years to estimate the number of averted deaths, non-fatal events, or disability adjusted life years. In each age-sex group, the total number of averted deaths from cardiovascular disease, prevalence of chronic kidney disease, and the death risk from cardiovascular disease in patients with chronic kidney disease (compared with others) were used to estimate the number of averted deaths from cardiovascular disease attributed to individuals with chronic kidney disease. For each chronic kidney disease stage (G3a, G3b, G4, and G5), estimates of the expected increase in potassium intake from replacement of dietary salt with potassium enriched salt substitutes, the dose-response relation of dietary and serum potassium, and pre-intervention serum potassium distribution were used to estimate the post-intervention serum potassium distribution. The serum potassium distributions (before and after the intervention) and known risk estimates of serum potassium with deaths from cardiovascular disease were used to calculate a PIF for each chronic kidney disease stage. The PIF and stage specific estimate of pre-intervention deaths from cardiovascular disease were used to calculate the additional deaths from cardiovascular disease. The additional deaths were subtracted from averted deaths to estimate net benefits (averted deaths) in individuals with chronic kidney disease exclusively and in the total adult population, including those with chronic kidney disease. Table 1 presents the model inputs and the appendix provides detailed information and rationales on model calculations and assumptions

equal to $15 \%$ of the mean for that specific group. In our primary model, we used the effect of a salt substitute on systolic blood pressure based on an evaluation of interim measurements (1-3 years after baseline) of 4705 participants in the ongoing Salt Substitute and Stroke Study (appendix 1). The use of salt substitutes was associated with lowered systolic blood pressure and the effects increased with age (table 1, eTables 2 and 3, and appendix 1). At a baseline age of 65, systolic blood pressure was reduced by $2.82 \mathrm{~mm} \mathrm{Hg}$ ( $95 \%$ confidence interval 0.89 to $4.75, \mathrm{P}=0.004$ ), and for each additional year of age, the effect was 0.13 $\mathrm{mm} \mathrm{Hg}(-0.02$ to $0.27, \mathrm{P}=0.09)$ larger for older ages or smaller for younger ages. The effects of changes in systolic blood pressure on cardiovascular disease outcomes, and the risk of chronic kidney disease, were based on the Global Burden of Disease Study and our previous meta-analysis (eTable 4). The prevalence of chronic kidney disease in each age and sex group was estimated by interpolation and extrapolation based on piecewise linear regression of the sex specific prevalence of chronic kidney disease in four age groups from the China National Survey of Chronic Kidney Disease, ${ }^{17}$ plotted against the midpoint age of each age group (appendix 2). Age specific hazard ratios for death from cardiovascular disease in individuals with chronic kidney disease (compared with others in the same age group) were estimated by interpolation and extrapolation of the log hazard ratio in four age groups, ${ }^{18}$ plotted against the midpoint age of each age group (appendix 2).

\section{Potassium model (potential harms)}

To estimate death rates from cardiovascular disease by stage of chronic kidney disease, before the intervention, we used: the 2015 estimates of deaths from cardiovascular disease from the Global Burden of Disease Study; the prevalence of each stage of chronic kidney disease from the China National Survey of Chronic Kidney Disease ${ }^{17}$; and hazard ratios for 


\section{Table 1 | Input data for comparative risk assessment on effect of nationwide salt substitute intervention in the adult Chinese population on cardiovascular disease burden}

Model and data Group Year Value Distribution Note

Blood pressure Group Year Value Distribution Note

Pre-intervention Sex, age $2015 \quad$ Age and sex specific $\quad v \quad$ Standard deviation of SBP in each group (Chinese adults aged

SBP estimates (eTable 1) 225) was assumed equal to $15 \%$ of the mean for that specific

group, based on age and sex specific SBP distributions estimated in $>500000$ Chinese adults. ${ }^{16}$ For each iteration $(n=1000)$, random draws from normal distributions of age-sex specific means from GBD were used to calculate assumed standard deviation and pparameters

Intervention Age N/A $-2.82(-4.75$ to -0.89$) \mathrm{mm} \mathrm{Hg}$ at age 65 Normal

effect on SBP Agears, with $0.13(-0.02$ to 0.27$) \mathrm{mm} \mathrm{Hg}$
lesser or greater reduction for each year of age younger or older than 65 , respectively

Estimates and their uncertainties of treatment effect and age-treatment interaction were estimated using interim measurements ( $1-3$ years after baseline) in $>4500$ participants of the SSaSS. For each iteration $(n=1000)$, random draws from normal distributions of main and interaction effects were used to calculate age specific effects on SBP

\begin{tabular}{|c|c|c|c|c|c|c|}
\hline $\begin{array}{l}\text { SBP effect on } \\
\text { CVD risk }\end{array}$ & Age & N/A & $\begin{array}{l}\text { Disease and age specific } \\
\text { estimates (eTable 4) }\end{array}$ & $\begin{array}{l}\text { Log } \\
\text { normal }\end{array}$ & $\begin{array}{l}\text { For each iteration ( } n=1000) \text {, random draws of age specific log } \\
\text { relative risks of CVD subtypes }(n=8) \text { were made }\end{array}$ & $\begin{array}{l}\text { GBD, } 2017^{*} \\
\text { Singh }^{23}\end{array}$ \\
\hline $\begin{array}{l}\text { SBP effect on } \\
\text { CKD risk }\end{array}$ & $\mathrm{N} / \mathrm{A}$ & N/A & $\begin{array}{l}\text { RR } 1.28(95 \% \mathrm{Cl} 1.18 \text { to } 1.39) \\
\text { per } 10 \mathrm{~mm} \mathrm{Hg}\end{array}$ & $\begin{array}{l}\text { Log } \\
\text { normal }\end{array}$ & For each iteration $(n=1000)$, random draws of log RR were made & GBD, $2014 \neq$ \\
\hline $\begin{array}{l}\text { Current CVD and } \\
\text { CKD burden }\end{array}$ & Sex, age & 2015 & $\begin{array}{l}\text { Disease, sex, and age } \\
\text { specific estimates }\end{array}$ & Normal & $\begin{array}{l}\text { Estimates and corresponding 95\% uncertainty intervals for } \\
\text { CVD subtypes }(n=11) \text { and CKD were retrieved from the GBD } \\
\text { Results Tool }\end{array}$ & $\begin{array}{l}\text { GBD Results } \\
\text { Tool§ }\end{array}$ \\
\hline
\end{tabular}

Prevalence of Sex, age 2007-10 Age and sex specific CKD (\%) $\quad$ estimates (eTable 1) Results Tool

GBD, 2017*

(n)

SSaSS

(unpublished) $\dagger$

Age and sex specific prevalence of CKD (eGFR $<60 \mathrm{~mL} /$ Zhang $^{17}$

$\mathrm{min} / 1.73 \mathrm{~m}^{2}$ ) was estimated by interpolation and extrapolation

based on piecewise linear regression of age specific CKD

prevalence in four age groups (18-39, 40-59, 60-69, $\left.\geq 70^{17}\right)$

plotted against the midpoint age of each age group. Similarly, $95 \%$

Cls for prevalence of CKD were estimated by interpolation and extrapolation based on piecewise linear regression of upper and lower $95 \% \mathrm{Cl}$ boundaries. For each iteration $(\mathrm{n}=1000)$, random draws of age and sex specific CKD prevalence (assuming normal distribution) were made

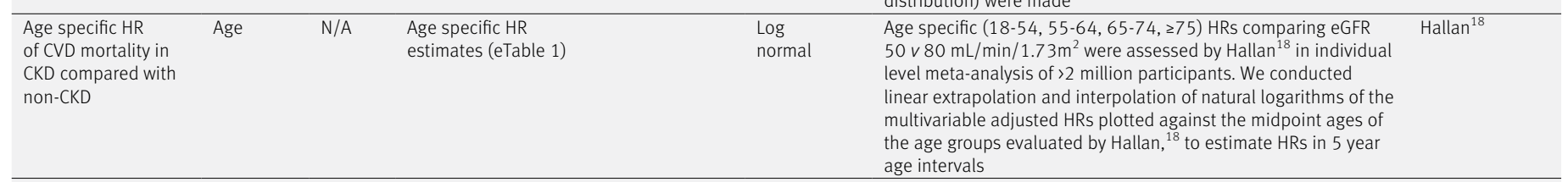

\begin{tabular}{|c|c|c|c|c|c|c|}
\hline \multicolumn{7}{|l|}{ Potassium } \\
\hline $\begin{array}{l}\text { Prevalence of CKD by } \\
\text { stage (\%) }\end{array}$ & CKD stage & $2007-10$ & $\begin{array}{l}\text { Stage G3a: } 1.40(95 \% \mathrm{Cl} 1.20 \text { to } 1.50) \text {; } \\
\text { stage } \mathrm{G} 3 \mathrm{~b}: 0.20(0.10 \text { to } 0.30) ; \text { stage } \mathrm{G} 4 \text { : } \\
0.10(0.06 \text { to } 0.20) \text {; stage } \mathrm{G} 5: 0.03(0.01 \\
\text { to } 0.05)\end{array}$ & Normal & $\begin{array}{l}\text { Prevalence of CKD per eGFR level in the adult Chinese population. } \\
\text { Random draws were made for each iteration }(n=1000)\end{array}$ & Zhang $^{17}$ \\
\hline $\begin{array}{l}\text { Crude HR of CVD } \\
\text { mortality compared } \\
\text { with non-CKD }\end{array}$ & CKD stage & $\mathrm{N} / \mathrm{A}$ & $\begin{array}{l}\text { Stage G3a: } 4.03 \\
\text { (95\% Cl } 2.76 \text { to } 5.88) \\
\text { stage G3b: } 6.95(4.35 \text { to } 11.10) \\
\text { stage G4: } 9.93 \text { (6.09 to } 16.17) \\
\text { stage G5: } 17.51 \text { (9.72 to } 31.55)\end{array}$ & $\begin{array}{l}\text { Log } \\
\text { normal }\end{array}$ & $\begin{array}{l}\text { Unadjusted HRs for each CKD stage using midpoint eGFR (ie, } \\
\text { stage } \mathrm{G} 3 \mathrm{a} 52.5 \text {, stage } \mathrm{G} 3 \mathrm{~b} 37.5 \text {, stage } \mathrm{G} 422.5 \text {, stage } \mathrm{G} 57.5 \\
\mathrm{~mL} / \mathrm{min} / 1.73 \mathrm{~m}^{2} \text { ) } v \text { reference point (eGFR } 95 \mathrm{~mL} / \mathrm{min} / 1.73 \mathrm{~m}^{2} \text { ) } \\
\text { were extracted from eFig } 7 \mathrm{~b} \text { in Matsushita. }{ }^{19} \mathrm{For} \text { each iteration } \\
\text { ( } \mathrm{n}=1000 \text { ), random draws of stage specific HR (assuming log } \\
\text { normal distribution) were made and used to calculate pre-inter- } \\
\text { vention CVD deaths per CKD stage }\end{array}$ & Matsushita $^{19}$ \\
\hline $\begin{array}{l}\text { Mean (SD) current } \\
\text { serum potassium } \\
\text { distribution (mmol/L) }\end{array}$ & CKD stage $^{4}$ & $\mathrm{~N} / \mathrm{A}$ & $\begin{array}{l}\text { Stage G3a: } 4.34(0.45) \\
\text { stage G3b: } 4.42(0.51) \\
\text { stage G4: } 4.52(0.59) \\
\text { stage G5: } 4.63(0.67)\end{array}$ & Normal & $\begin{array}{l}\text { Extrapolated and interpolated from linear regressions of means and } \\
\text { standard deviations of stage } \mathrm{G} 3 \text { and } \geq \mathrm{G} 4 \text { reported by the CKD-PC. } \\
\text { For each iteration ( } \mathrm{n}=1000 \text { ), random draws of stage specific serum } \\
\text { potassium levels (assuming normal distribution) were made }\end{array}$ & Kovesdy $^{8}$ \\
\hline $\begin{array}{l}\text { Increase in potassium } \\
\text { intake by salt } \\
\text { substitute intervention } \\
\text { (g/day) }\end{array}$ & $\mathrm{N} / \mathrm{A}$ & $\mathrm{N} / \mathrm{A}$ & $0.86(95 \% \mathrm{Cl} 1.14$ to 0.68$)$ & Normal & $\begin{array}{l}\text { Calculated by multiplying urinary excretion in SSaSS } \\
(0.66 \mathrm{~g} / 24 \text { hours; } 95 \% \mathrm{Cl} 0.52 \text { to } 0.80) \text { by a factor of } 1.3 \text { based } \\
\text { on mean differences between intake and excretion }{ }^{20}\end{array}$ & Huang $2018^{\star *}$ \\
\hline $\begin{array}{l}\text { Dietary potassium } \\
\text { effect on serum potas- } \\
\text { sium level } \\
\text { (mmol/L per } \mathrm{g} / \text { day })\end{array}$ & CKD stage $^{4}$ & $\mathrm{~N} / \mathrm{A}$ & $\begin{array}{l}\text { Stage G3a: } 0.23 \text { ( } 95 \% \mathrm{Cl} 0.08 \text { to } 0.38) \\
\text { stage G3b: } 0.47 \text { ( } 0.33 \text { to } 0.61) \\
\text { stage G4: } 0.93 \text { ( } 0.66 \text { to } 1.21) \\
\text { stage G5: } 1.87 \text { ( } 1.33 \text { to } 2.41)\end{array}$ & Normal & $\begin{array}{l}\text { Estimated in clinical trial; } \\
\beta \text { and SE assumed to be } 2 \times \text { effect estimated in stage G3a; } \\
\beta \text { and SE assumed to be } 4 \times \text { effect estimated in stage G3a; } \\
\beta \text { and SE assumed to } 8 \times \text { effect estimated in stage G3a }\end{array}$ & $\begin{array}{l}\text { Turban } \\
\text { (unpublished)+† }\end{array}$ \\
\hline $\begin{array}{l}\text { Serum potassium } \\
\text { effect on CVD } \\
\text { mortality }\end{array}$ & $\mathrm{N} / \mathrm{A}$ & $\mathrm{N} / \mathrm{A}$ & $\begin{array}{l}\mathrm{HR}(95 \% \mathrm{Cl}) \text { compared with serum } \\
\text { potassium } 4.2 \mathrm{mmol} / \mathrm{L} \text { available for each } \\
0.05 \text { increment of serum potassium in the } \\
\text { interval } 4.2 \text { to } 6.5 \mathrm{mmol} / \mathrm{L}\end{array}$ & $\begin{array}{l}\text { Log } \\
\text { normal }\end{array}$ & $\begin{array}{l}\text { CKD-PC data suggest no evidence of } \\
\text { different HR per eGFR level }\end{array}$ & Kovesdy $^{8}$ \\
\hline
\end{tabular}

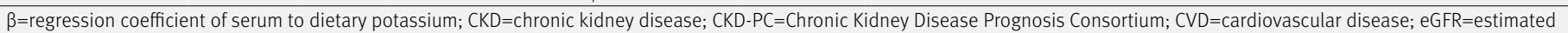

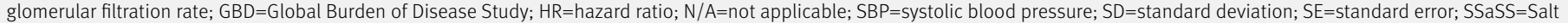
Substitute and Stroke Study; RR=relative risk.

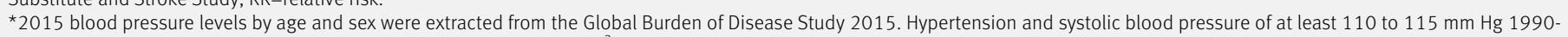
2015. Seattle: Institute for Health Metrics and Evaluation (IHME), 2017. ${ }^{3}$

tEffects on systolic blood pressure and potassium intake were assessed in the ongoing Salt Substitute and Stroke Study, a cluster randomised trial conducted in 600 villages across five Chinese provinces.

¥Global Burden of Metabolic Risk Factors for Chronic Diseases Collaboration. Cardiovascular disease, chronic kidney disease, and diabetes mortality burden of cardiometabolic risk factors from 1980 to 2010: a comparative risk assessment. Lancet Diabetes Endocrinol 2014;2:634-47 (reference 10 from web appendix).

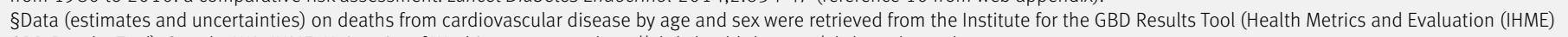
GBD Results Tool). Seattle, WA: IHME, University of Washington, 2019. http://ghdx.healthdata.org/gbd-results-tool.

IChronic kidney disease stages: G3a (estimated glomerular filtration rate $45-59 \mathrm{~mL} / \mathrm{min} / 1.73 \mathrm{~m}^{2}$ ); G3b (30-44); G4 (15-29); and G5 («15-29).

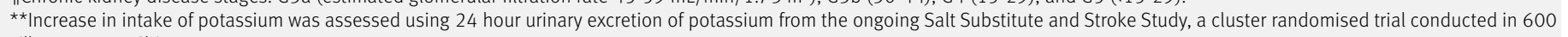
villages across China.

t+The effects of dietary potassium on blood pressure in adults with stage 3 chronic kidney disease: Results from the CKD-K trial (unpublished data). 
death from cardiovascular disease by stage of chronic kidney disease from the Chronic Kidney Disease Prognosis Consortium. ${ }^{19}$ The estimated increase in potassium intake from salt substitution $(30 \pm 10 \%$ potassium chloride) was based on the increase in urinary excretion of potassium in 24 hours in the Salt Substitute and Stroke Study, multiplied by a factor of 1.3 , based on the mean differences between intake and excretion (appendix 3). ${ }^{20}$

We used data from an unpublished randomised controlled trial (clinicalTrials.gov NCT00949585) investigating potassium supplementation in patients with moderate chronic kidney disease to estimate the dose-response relation between dietary and serum potassium in patients with chronic kidney disease stage G3a (appendix 4). The two period crossover trial included 29 patients with chronic kidney disease stage G3a (mean estimated glomerular filtration rate $54.5 \mathrm{~mL} / \mathrm{min} / 1.73 \mathrm{~m}^{2}$; mean age $67 ; 59 \%$ women; 24\% with diabetes; $93 \%$ with hypertension; and 59\% receiving angiotensin converting enzyme inhibitors or angiotensin II receptor blockers) who were assigned to diets providing 100 and $40 \mathrm{mmol} /$ day of potassium in two four week periods. We used serum measurements of potassium obtained one week after the start of each feeding period. Mean serum concentration of potassium was 0.55 (95\% confidence interval 0.38 to 0.72$) \mathrm{mmol} / \mathrm{L}$ greater at the higher dose compared with the lower dose, which is equivalent to 0.23 (0.08 to 0.38$) \mathrm{mmol} / \mathrm{L}$ greater serum concentration of potassium for each additional gram of dietary potassium daily.

Based on a recent expert consensus statement, we assumed that measurable changes in serum concentrations of potassium from a potassium enriched salt substitute could occur in chronic kidney disease stages G3a and higher. ${ }^{21} 22$ In the primary model, we assumed that the dose-response relation in chronic kidney disease stage G3a would double with each increasing stage of chronic kidney disease (appendix 4). We derived means and standard deviations of serum concentrations of potassium for each of four chronic kidney disease stages (G3a, G3b, G4, and G5) by extrapolation of data reported for stages G3a-G3b and G4-G5 in a pooled analysis of 25 international cohorts (appendix 4). ${ }^{8}$ We used relative risks of serum potassium with deaths from cardiovascular disease from the same pooled analysis. ${ }^{8}$

\section{Statistical analysis}

Blood pressure model

Incorporating estimates and uncertainty for systolic blood pressure measurements and outcomes in the 2015 population, the intervention effects on systolic blood pressure, and the associations of systolic blood pressure with risk of cardiovascular disease and chronic kidney disease, we calculated the potential impact fraction of the intervention for each outcome, separately in 24 age and sex groups, overall and in the subset of the population with chronic kidney disease (appendix 2). The potential impact fraction (PIF) for each outcome (o) was defined as: $\mathrm{PIF}_{\text {oas }}=\left(\int_{\mathrm{x}=0}^{\mathrm{m}} \mathrm{RR}_{\mathrm{oa}}(\mathrm{x})\right.$ $\left.\mathrm{P}_{\text {as }}(\mathrm{x}) \mathrm{dx}-\int_{\mathrm{x}=0}^{\mathrm{m}} \mathrm{RR}_{\mathrm{oa}}(\mathrm{x}) \mathrm{P}^{\prime}{ }_{\text {as }}(\mathrm{x}) \mathrm{dx}\right) \div\left(\int_{\mathrm{x}=0}^{\mathrm{m}} \mathrm{RR}_{\mathrm{oa}}(\mathrm{x}) \mathrm{P}_{\mathrm{as}}(\mathrm{x}) \mathrm{dx}\right)$, where $\mathrm{P}_{\mathrm{as}}(\mathrm{x})$ and $\mathrm{P}_{\text {as }}(\mathrm{x})$ are the pre-intervention and post-intervention systolic blood pressure distributions in age group (a) and sex (s). $R_{\mathrm{oa}}(\mathrm{x})$ is the relative risk as a function of systolic blood pressure (x), outcome (o), and age $(\mathrm{a}): \mathrm{RR}_{\mathrm{oa}}(\mathrm{x})=\mathrm{e}^{(\operatorname{lnRRoa}(\mathrm{x}-\mathrm{TMREL}) \div 10)}$, where $\ln \mathrm{RR}_{\mathrm{oa}}$ is the increase in the natural logarithm of the relative risk of outcome (o) in age (a) for each $10 \mathrm{~mm} \mathrm{Hg}$ increase in systolic blood pressure, derived from previous metaanalyses, ${ }^{323}$ and TMREL is the theoretical minimum risk exposure level (that is, $110-115 \mathrm{~mm} \mathrm{Hg}$ ). ${ }^{3}$

The number of cardiovascular events prevented were computed by multiplying an age, sex, and cause specific potential impact fraction by the estimated current number of cardiovascular events for the same group. The total numbers of averted events were calculated as the sum of estimates over all groups and we summed subtype specific estimates to generate estimates for total cardiovascular disease. We excluded inflammatory heart diseases from the estimations of non-fatal events and disability adjusted life years because these diseases develop independently of increases in blood pressure. These conditions were included in the estimation of death rates, however, because a lower blood pressure will benefit and reduce deaths from heart failure similarly in those individuals. $^{23}$ In each group, we also computed prevented deaths from cardiovascular disease in individuals with chronic kidney disease (appendix 2).

\section{Potassium model}

To estimate the additional deaths from cardiovascular disease from increased intake of potassium in individuals with chronic kidney disease, we computed the potential impact fraction (PIF) for deaths from cardiovascular disease for each stage of chronic kidney disease (e) as: $\mathrm{PIF}_{\mathrm{e}}=\left(\sum_{\mathrm{x}=0}^{\mathrm{m}} \mathrm{RR}(\mathrm{x}) \mathrm{P}_{\mathrm{e}}(\mathrm{x})-\sum_{\mathrm{x}=0}^{\mathrm{m}} \mathrm{RR}(\mathrm{x})\right.$ $\left.\mathrm{P}_{\mathrm{e}}^{\prime}(\mathrm{x})\right) \div\left(\sum_{\mathrm{x}=0}^{\mathrm{m}} \mathrm{RR}(\mathrm{x}) \mathrm{P}_{\mathrm{e}}(\mathrm{x})\right)$, where $\mathrm{P}_{\mathrm{e}}(\mathrm{x})$ and $\mathrm{P}_{\mathrm{e}}^{\prime}(\mathrm{x})$ are the pre-intervention and post-intervention distributions of serum potassium in chronic kidney disease stage e. $\mathrm{RR}(\mathrm{x})$ is the relative risk of death from cardiovascular disease at serum potassium concentration $\mathrm{x}$, and was reported for each $0.05 \mathrm{mmol} / \mathrm{L}$ increase in serum potassium in a pooled analysis of 25 cohort studies. ${ }^{8}$ The additional deaths from cardiovascular disease (that is, negative of averted deaths from cardiovascular disease) from the intervention were computed by multiplying the negative of the potential impact fraction in each group by the number of deaths from cardiovascular disease in the same group before the intervention. We summed group specific effects to derive total additional deaths for all individuals with chronic kidney disease.

\section{Estimating intervention net effects on deaths from cardiovascular disease}

The net averted deaths from cardiovascular disease were calculated as the difference between averted deaths caused by a reduction in systolic blood pressure and additional deaths caused by an increase in 
serum concentrations of potassium (appendix 5). We also calculated the benefit-to-risk ratio by dividing the averted deaths from a reduction in systolic blood pressure by the additional deaths related to hyperkalaemia. The net effects, expressed as absolute number, percentage of current number of deaths from cardiovascular disease, and the benefit-to-risk ratio, were calculated for the whole population and for those with chronic kidney disease.

\section{Uncertainty analysis}

We quantified uncertainty in all analyses with probabilistic sensitivity analyses in Monte Carlo simulations, jointly incorporating group specific uncertainties in input parameters. For each simulation, a draw was made from the distributions of: current mean systolic blood pressure for the specific agesex group; the theoretical minimum risk exposure level; the effect of salt substitutes on systolic blood pressure; the age-salt substitute interaction effect on systolic blood pressure; the effects of systolic blood pressure on each cardiovascular disease outcome; the current number of events (eg, deaths) for each cardiovascular disease outcome; the prevalence of chronic kidney disease in each group; and the hazard ratio for deaths from cardiovascular disease in patients with chronic kidney disease compared with others in the same age group. Uncertainty in the theoretical minimum risk exposure level was propagated by sampling between the $110-115 \mathrm{~mm} \mathrm{Hg}$ interval each time the potential impact fraction was calculated. ${ }^{3}$ For each simulation of the potassium model, a draw was made from the distributions of: increased potassium intake; total deaths from cardiovascular disease; stage specific prevalence of chronic kidney disease; and relative risk of serum potassium with deaths from cardiovascular disease. Similarly, draws were made for the group specific distributions of: risk of deaths from cardiovascular disease; relation between diet and serum potassium; and serum concentrations of potassium. For each simulation of the blood pressure and potassium models, the net averted deaths were calculated as the difference between averted and additional deaths. We derived the corresponding central estimate for each endpoint (including benefits, harms, and net effects) from the 50th centile, and the $95 \%$ uncertainty interval from the 2.5th and 97.5th centiles of 1000 modelling runs.

\section{Sensitivity analyses}

In our primary model, we used a conservative approach in selecting input data to avoid overestimation of benefits and underestimation of harms. A strength of modelling approaches is the ability to assess how findings can vary in response to a range of reasonable assumptions. To evaluate the robustness of the primary model, we conducted several sensitivity analyses by changing key model assumptions and inputs (appendix 6 and eTable 6). We evaluated the impact of varying intervention coverage by assuming 50\% higher or $50 \%$ lower reductions in systolic blood pressure and increases in potassium intake compared with that observed in the Salt Substitute and Stroke Study. We estimated the net effect on deaths from cardiovascular disease assuming that all individuals with chronic kidney disease, aware of their diagnosis (about 14\% of individuals with chronic kidney disease stages $\geq \mathrm{G} 3 \mathrm{a}),{ }^{10}{ }^{17}$ would avoid salt substitutes; for this sensitivity analysis, we used published data on prevalence $^{17}$ and awareness ${ }^{10}$ of chronic kidney disease in China, and assumed neither benefits nor risks of the intervention in the proportion of individuals with chronic kidney disease who were aware of their diagnosis.

Using alternative effects from three meta-analyses of studies of salt substitutes, we varied the impact of potassium enriched salt substitutes on systolic blood pressure. ${ }^{5624}$ Hernandez et al evaluated the effects on systolic blood pressure and urinary excretion of potassium in salt substitute trials. ${ }^{24}$ Thus we used estimates for reduction in systolic blood pressure and potassium excretion to simultaneously change our assumptions on potassium intake and effects on systolic blood pressure (eTable 6). Whereas a reduction in sodium is associated with lower systolic blood pressure in people with normal and high blood pressure, ${ }^{4}$ and meta-analyses of salt substitute trials have consistently reported reductions in blood pressure in individuals with hypertension, ${ }^{5624}$ limited evidence exists for the effects of salt substitutes on systolic blood pressure in people with normal blood pressure. ${ }^{5624}$ Thus we conducted a sensitivity analysis assuming no effect of salt substitution on systolic blood pressure in people with normal blood pressure based on the prevalence of hypertension by age and sex from a recent survey of 1.7 million Chinese people. ${ }^{2}$

We evaluated the impact of a stronger or weaker dose-response relation between dietary and serum potassium by assuming that the serum response increases either exponentially or linearly, respectively, with decreasing estimated glomerular filtration rate, and investigated the impact of assuming the same serum response to potassium dose in chronic kidney disease stages G3b, G4, and G5 as estimated in stage G3a (eTable 6). We varied the standard deviation of systolic blood pressure in each age-sex group $(10 \%$ and $20 \%$ of the mean). To evaluate how salt substitutes and potassium content influence the estimated additional deaths from cardiovascular disease in individuals with chronic kidney disease, we varied the proportion of discretionary salt replaced by salt substitutes (10$100 \%)$ and the content of potassium chloride in salt substitutes ( $10 \%$ or $25 \%)$.

Finally, we evaluated a hypothetical extreme scenario with a combination of assumptions to maximise the number of estimated additional deaths due to hyperkalaemia but limiting the number of estimated averted deaths from a reduction in blood pressure, including assuming: 50\% greater use of salt substitutes; the benefits on blood pressure occurring exclusively in individuals with hypertension; and an exponential increase in the relation between diet 
and serum potassium by declining kidney function. All analyses were performed with RStudio, version 1.1.423.

\section{Patient and public involvement}

No patients were involved in setting the research question or the outcome measures, nor were they involved in developing plans for design or implementation of the study. No patients were asked to advise on interpretation or writing up of results.

\section{Results}

The overall effects of salt substitution on systolic blood pressure were estimated to prevent about 461000 deaths (95\% uncertainty interval 196339 to 704438) from cardiovascular disease annually, including 208000 (89366 to 328249 ) due to stroke and 175000 (71016 to 271720) due to ischaemic heart disease (table 2). These averted deaths corresponded to $10.9 \%$ ( $4.7 \%$ to $16.8 \%)$ of baseline deaths from cardiovascular disease. The effects of the intervention on systolic blood pressure could also avert an estimated 743000 (305803 to 1273098) non-fatal cardiovascular events annually, including about 365000 (150524 to 623 309) strokes, 147000 (62335 to 241590) ischaemic heart disease events, and 7.9 million (3.3 to 12.9) disability adjusted life years related to cardiovascular disease annually. The effects on systolic blood pressure were also estimated to decrease the incidence of chronic kidney disease by about 120000 (47889 to 199075) annually, corresponding to $6.9 \%(2.8 \%$ to $11.4 \%)$ of the total number of cases of incident chronic kidney disease.

Averted deaths from cardiovascular disease were mainly in older adults $(\geq 70)$ because of the age related differences in the risk of death, but averted non-fatal cardiovascular events and disability adjusted life years were more evenly distributed across ages (eFigs 1-3). In about 17.2 million (95\% uncertainty interval 14.6 to 19.7) individuals with chronic kidney disease (stages $\geq G 3 a$ ), the effects of the intervention on systolic blood pressure could prevent an estimated 32000 deaths (12261 to 54453) from cardiovascular disease.

In individuals with chronic kidney disease (stages $\geq \mathrm{G} 3 \mathrm{a}$ ), increased intake of potassium and serum concentrations of potassium were estimated to potentially

\begin{tabular}{|c|c|c|c|}
\hline \multirow[b]{2}{*}{ Metric and disease } & \multirow{2}{*}{$\begin{array}{l}\text { Current No (000s) of events } \\
(95 \% \text { UI) }\end{array}$} & \multicolumn{2}{|c|}{ Averted No of events ( $95 \%$ UI) } \\
\hline & & In 000s & $\%$ of current \\
\hline \multicolumn{4}{|l|}{ Deaths/year } \\
\hline Total cardiovascular disease* & $4201(4157$ to 4246$)$ & 461 (196 to 704) & $10.9(4.7$ to 16.8$)$ \\
\hline Ischaemic heart disease & 1689 (1666 to 1715$)$ & 175 (71 to 272$)$ & $10.3(4.2$ to 16.2$)$ \\
\hline Stroke: & 2034 (2012 to 2056) & 208 (89 to 328$)$ & $10.2(4.4$ to 16.1$)$ \\
\hline Ischaemic & 815 (801 to 829$)$ & 77 (32 to 123$)$ & $9.4(4.0$ to 15.0$)$ \\
\hline Haemorrhagic & $1219(1201$ to 1236$)$ & 130 (56 to 209) & $10.7(4.6$ to 17.1$)$ \\
\hline Other cardiovascular disease & $477(448$ to 506$)$ & 75 (32 to 114$)$ & 15.8 (6.9 to 23.6$)$ \\
\hline Chronic kidney disease & $171(167$ to 176$)$ & 15 (6 to 23$)$ & 8.5 (3.6 to 13.3$)$ \\
\hline \multicolumn{4}{|l|}{ Non-fatal events/year } \\
\hline Total cardiovascular disease $\neq$ & 9455 (9204 to 9727) & $743(306$ to 1273$)$ & $7.9(3.2$ to 13.4$)$ \\
\hline Ischaemic heart disease & 1546 (1445 to 1657$)$ & 147 (62 to 242$)$ & 9.5 (4.0 to 15.5$)$ \\
\hline Strokeף: & $4022(3887$ to 4161$)$ & 365 (151 to 623) & 9.1 (3.7 to 15.4$)$ \\
\hline Ischaemic & $2636(2503$ to 2771$)$ & $232(96$ to 385$)$ & 8.8 (3.6 to 14.6$)$ \\
\hline Haemorrhagic $\rrbracket$ & 1386 (1340 to 1429$)$ & 131 (52 to 239) & $9.5(3.7$ to 17.2$)$ \\
\hline Other cardiovascular disease§ & 3891 (3697 to 4096) & $230(82$ to 418$)$ & $5.9(2.2$ to 10.7$)$ \\
\hline Chronic kidney disease & 1741 (1596 to 1885$)$ & 120 (48 to 199$)$ & $6.9(2.8$ to 11.4$)$ \\
\hline \multicolumn{4}{|c|}{ Disability adjusted life years/year } \\
\hline Total cardiovascular disease ${ }^{\star \star}$ & 82006 (81 292 to 82722$)$ & 7947 (3310 to 12891) & 9.7 (4.0 to 15.7$)$ \\
\hline Ischaemic heart disease & $29804(29452$ to 30191$)$ & 2701 (1115 to 4390) & $9.1(3.7$ to 14.7$)$ \\
\hline Stroke: & $42554(42040$ to 43025$)$ & $4013(1692$ to 6620$)$ & $9.5(4.0$ to 15.5$)$ \\
\hline Ischaemic & 17401 (17028 to 17796$)$ & 1602 (678 to 2523$)$ & $9.2(3.9$ to 14.5$)$ \\
\hline Haemorrhagic & 25139 (24806 to 25468$)$ & 2397 (954 to 4183) & $9.6(3.8$ to 16.6$)$ \\
\hline Other cardiovascular diseaset† & 9664 (9309 to 9987) & $1249(563$ to 1933$)$ & 12.9 (5.7 to 19.9$)$ \\
\hline Chronic kidney disease & $4684(4572$ to 4793$)$ & 303 (126 to 506) & $6.5(2.7$ to 10.8$)$ \\
\hline \multicolumn{4}{|c|}{$\begin{array}{l}\text { UI=uncertainty interval. } \\
\text { *Includes ischaemic heart disease, stroke (ischaemic and haemorrhagic), and other cardiovascular diseases (aortic aneurysm, hypertensive heart disease, } \\
\text { rheumatic heart disease, endocarditis, atrial fibrillation, myocarditis, cardiomyopathy, peripheral artery disease, and other cardiovascular and circulatory } \\
\text { diseases). } \\
\text { tIncludes aortic aneurysm, hypertensive heart disease, rheumatic heart disease, endocarditis, atrial fibrillation, myocarditis, cardiomyopathy, peripheral } \\
\text { artery disease, and other cardiovascular and circulatory diseases. } \\
\text { fIncludes ischaemic heart disease, stroke (ischaemic and haemorrhagic), and other cardiovascular diseases (atrial fibrillation and peripheral artery } \\
\text { disease). } \\
\text { \$Includes atrial fibrillation and peripheral artery disease. } \\
\text { IIncludes only first events. } \\
\text { **Includes ischaemic heart disease, stroke (ischaemic and haemorrhagic), and other cardiovascular diseases (aortic aneurysm, hypertensive heart } \\
\text { disease, atrial fibrillation, peripheral artery disease, and other cardiovascular and circulatory diseases), but not rheumatic heart disease, endocarditis, } \\
\text { myocarditis, or cardiomyopathy. } \\
+† \text { Includes aortic aneurysm, hypertensive heart disease, atrial fibrillation, peripheral artery disease, and other cardiovascular and circulatory diseases, but } \\
\text { not rheumatic heart disease, endocarditis, myocarditis, or cardiomyopathy. }\end{array}$} \\
\hline
\end{tabular}




\begin{tabular}{|c|c|c|c|c|}
\hline \multirow[b]{2}{*}{ Analyses } & \multirow{2}{*}{$\begin{array}{l}\text { Averted deaths (000s) } \\
\text { from reduction in SBP } \\
(95 \% \mathrm{UI})\end{array}$} & \multirow{2}{*}{$\begin{array}{l}\text { Additional deaths } \\
(000 \mathrm{~s}) \text { from increased } \\
\text { serum potassium } \\
(95 \% \mathrm{UI})\end{array}$} & \multicolumn{2}{|c|}{ Net averted deaths from CVD ( $95 \%$ UI) } \\
\hline & & & In $000 \mathrm{~s}$ & $\%$ of current \\
\hline Primary model & $32.2(12.3$ to 54.5$)$ & $10.6(6.4$ to 16.6$)$ & $21.4(1.9$ to 42.9$)$ & 7.5 (0.6 to 13.8$)$ \\
\hline \multicolumn{5}{|l|}{ Sensitivity analyses } \\
\hline \multicolumn{5}{|l|}{ Coverage: } \\
\hline Lesser ( $50 \%$ of primary model) & $16.7(6.2$ to 28.6$)$ & $5.6(3.3$ to 8.7$)$ & $11.1(1.0$ to 22.6$)$ & $3.9(0.3$ to 7.4$)$ \\
\hline Greater $(150 \%$ of primary model) & $46.6(18.2$ to 77.5$)$ & $14.9(9.2$ to 23.5$)$ & $31.5(3.2$ to 61.0$)$ & $11.1(1.2$ to 19.7$)$ \\
\hline $\begin{array}{l}\text { Patients aware of having chronic kidney } \\
\text { disease avoid salt substitutes }\end{array}$ & $31.9(12.2$ to 54.1$)$ & $8.5(5.1$ to 13.1$)$ & 23.1 (3.9 to 44.6) & $8.2(1.5$ to 14.5$)$ \\
\hline \multicolumn{5}{|c|}{ Alternative blood pressure effects of salt substitutes: } \\
\hline About $75 \%$ greater $^{5}$ & $40.8(22.2$ to 66.9$)$ & $10.6(6.4$ to 16.6$)$ & 30.3 (11.2 to 54.2$)$ & $10.8(3.8$ to 17.6$)$ \\
\hline About $100 \%$ greater $^{6}$ & $45.6(29.3$ to 68.2$)$ & $10.6(6.4$ to 16.6$)$ & $35.0(20.8$ to 55.8$)$ & $12.3(8.3$ to 16.8$)$ \\
\hline About $180 \%$ greater ${ }^{24} \dagger$ & $61.8(42.1$ to 91.2$)$ & $10.6(6.4$ to 16.6$)$ & 51.1 (34.9 to 76.3$)$ & $17.8(14.3$ to 21.8$)$ \\
\hline $\begin{array}{l}\text { Effect only in people with } \\
\text { hypertension }\end{array}$ & $25.3(10.7$ to 44.4$)$ & 10.6 (6.4 to 16.6$)$ & 14.7 (0.1 to 31.8$)$ & $5.2(0.0$ to 10.5$)$ \\
\hline \multicolumn{5}{|c|}{ Dose-response relation of serum to dietary potassium intake: } \\
\hline Stronger $\neq$ & $32.2(12.3$ to 54.5$)$ & $11.9(6.9$ to 19.1$)$ & $20.1(1.1$ to 41.4$)$ & $7.0(0.4$ to 13.6$)$ \\
\hline Weaker§ & $32.2(12.3$ to 54.5$)$ & $7.5(4.7$ to 11.7$)$ & $24.3(5.2$ to 45.9$)$ & $8.6(2.0$ to 14.9$)$ \\
\hline $\begin{array}{l}\text { Equal over chronic kidney disease } \\
\text { stages G3a-G5 }\end{array}$ & $32.2(12.3$ to 54.5$)$ & $5.8(3.6$ to 9.0$)$ & $26.1(7.2$ to 47.6$)$ & $9.2(2.7$ to 15.4$)$ \\
\hline \multicolumn{5}{|c|}{$\begin{array}{l}\mathrm{SBP}=\text { systolic blood pressure; } \mathrm{UI}=\text { uncertainty interval; } \mathrm{CVD}=\text { cardiovascular disease; } \mathrm{CKD}=\text { chronic kidney disease. } \\
\text { *Include deaths from ischaemic heart disease, stroke (ischaemic and haemorrhagic), and other cardiovascular diseases (aortic aneurysm, } \\
\text { hypertensive heart disease, atrial fibrillation, cardiomyopathy, peripheral artery disease, and other cardiovascular and circulatory diseases). } \\
\text { tHernandez et al conducted meta-analyses to evaluate the effect of salt substitutes on blood pressure and } 24 \text { hour excretion of potassi- } \\
\text { um. }{ }^{24} \text { Estimates for excretion of potassium in } 24 \text { hours ( } 11.5 \mathrm{mmol} / \text { day, } 95 \% \text { confidence interval } 8.4 \text { to } 14.6 \text { ) were multiplied by a factor of } \\
1.3 \text { to estimate the corresponding increase in potassium intake and changed the assumptions of the effects of blood pressure and potassi- } \\
\text { um intake in the sensitivity analysis. } \\
\text { fIncreasing exponentially with decreasing kidney function. } \\
\text { §Increasing linearly with decreasing kidney function. }\end{array}$} \\
\hline
\end{tabular}

result in about 11000 (95\% uncertainty interval 6422 to 16562) additional deaths from cardiovascular disease (table 3 ). About half (42\%) of the additional deaths related to hyperkalaemia were in individuals with advanced chronic kidney disease (stages G4-G5), who represent about $8 \%$ of all Chinese individuals with chronic kidney disease, ${ }^{17}$ and contribute to about $17 \%$ of current deaths from cardiovascular disease in individuals with chronic kidney disease (eTable 7).

The estimated net effect of the modelled intervention was about 450000 (95\% uncertainty interval 183699 to 697084 ) fewer deaths from cardiovascular disease annually in the overall population (about 11\% of all deaths from cardiovascular disease) and around 21000 (1928 to 42926) fewer deaths from cardiovascular disease annually in individuals with chronic kidney disease (about $8 \%$ of all deaths from cardiovascular disease; table 3 and table 4). The ratio of averted deaths caused by a reduction in systolic blood pressure compared with additional deaths due to hyperkalaemia was about 43:1 (95\% uncertainty interval16:1 to $83: 1$ ) in the whole population and three to one $(3.1: 1,1.2: 1$ to $5.4: 1)$ in individuals with chronic kidney disease (fig 2).

\section{Sensitivity analyses}

Although the estimates of absolute averted and additional deaths varied in the sensitivity analyses (eFigs 4-5), substantial net benefits were consistently seen in the total population (table 4) and in those with chronic kidney disease (table 3 ), with averted deaths far outweighing additional deaths (fig 2). A $50 \%$ greater or lesser use of salt substitutes would increase or decrease the number of averted (total and net) and additional deaths by around 50\%, respectively, compared with the primary model, but the ratio of averted to additional deaths would be largely unchanged. Although having a minimal effect on averted deaths (1\% fewer), avoidance of salt substitutes in patients with chronic kidney disease aware of their diagnosis reduced the estimated additional deaths by $20 \%$ and resulted in $8 \%$ more net averted deaths compared with the primary model. Comparing the effects on systolic blood pressure from the three meta-analyses, rather than the Salt Substitute and Stroke Study, increased the estimated averted deaths compared with the primary model. When we used the effects on systolic blood pressure from Peng et al, 40\% more averted deaths were estimated, and from Newberry et al, 55\% more averted deaths were estimated (table 4). ${ }^{5}$ When we simultaneously used the effect on systolic blood pressure and potassium dose estimated in a recent meta-analysis by Hernandez et al, the averted deaths increased (109\% more) but additional deaths related to hyperkalaemia were reduced (30\% fewer). ${ }^{24}$ Assuming a blood pressure effect only in individuals with hypertension, the number of averted deaths was reduced to $76 \%$ of the primary model.

When we assumed an exponential increase in the dose-response relation between dietary and serum potassium by decreasing kidney function, 


\begin{tabular}{|c|c|c|c|c|c|c|c|}
\hline \multirow[b]{2}{*}{ Analyses } & \multicolumn{2}{|c|}{$\begin{array}{l}\text { Averted deaths from SBP reduction in } \\
\text { total population }(95 \% \mathrm{UI})\end{array}$} & \multicolumn{2}{|c|}{$\begin{array}{l}\text { Additional deaths from } \\
\text { increased serum potassium in } \\
\text { patients with CKD }(95 \% \text { UI) }\end{array}$} & \multicolumn{3}{|c|}{ Net averted deaths from CVD (95\% UI) } \\
\hline & In 000s & $\begin{array}{l}\text { Per } 100000 \\
\text { adults exposedt }\end{array}$ & In 000s & $\begin{array}{l}\text { Per } 100000 \\
\text { adults exposedt }\end{array}$ & In $000 \mathrm{~s}$ & $\begin{array}{l}\text { Per } 100000 \text { adults } \\
\text { exposedt }\end{array}$ & $\%$ of current \\
\hline Primary model & $\begin{array}{l}460.7 \\
(196.3 \text { to } 704.4)\end{array}$ & $\begin{array}{l}45.9 \\
(19.8 \text { to } 71.9)\end{array}$ & $\begin{array}{l}10.6 \\
(6.4 \text { to } 16.6)\end{array}$ & 1.1 (0.6 to 1.7$)$ & 449.5 (183.7 to 697.1) & 44.8 (18.8 to 70.8$)$ & 10.7 (4.4 to 16.5$)$ \\
\hline \multicolumn{8}{|l|}{ Sensitivity analyses } \\
\hline \multicolumn{8}{|l|}{ Coverage: } \\
\hline $\begin{array}{l}\text { Lesser ( } 50 \% \text { of primary } \\
\text { model) }\end{array}$ & $\begin{array}{l}239.1 \\
\text { (99.6 to 372.1) }\end{array}$ & $\begin{array}{l}23.8 \\
\text { (10.1 to } 37.9)\end{array}$ & $\begin{array}{l}5.6 \\
(3.3 \text { to } 8.7)\end{array}$ & $0.6(0.3$ to 0.9$)$ & 233.3 (93.2 to 368.0$)$ & $23.2(9.5$ to 37.4$)$ & $5.5(2.2$ to 8.7$)$ \\
\hline $\begin{array}{l}\text { Greater }(150 \% \text { of } \\
\text { primary model) }\end{array}$ & $\begin{array}{l}666.3 \\
(288.2 \text { to } 1,003.5) \\
\end{array}$ & $\begin{array}{l}66.3 \\
(29.3 \text { to } 102.4)\end{array}$ & $\begin{array}{l}14.9 \\
(9.2 \text { to } 23.5)\end{array}$ & $1.5(0.9$ to 2.4$)$ & 651.5 (270.8 to 987.6$)$ & $65.0(27.7$ to 100.9$)$ & 15.5 (6.5 to 23.5$)$ \\
\hline $\begin{array}{l}\text { Patients aware of having } \\
\text { chronic kidney disease } \\
\text { avoid salt substitutes }\end{array}$ & $\begin{array}{l}457.1 \\
(195.0 \text { to } 699.5)\end{array}$ & $\begin{array}{l}45.5 \\
(19.7 \text { to } 71.4)\end{array}$ & $\begin{array}{l}8.5 \\
(5.1 \text { to } 13.1)\end{array}$ & $0.9(0.5$ to 1.4$)$ & 448.5 (185.1 to 693.5$)$ & $44.6(18.8$ to 70.6$)$ & $10.6(4.4$ to 16.5$)$ \\
\hline \multicolumn{8}{|c|}{ Alternative blood pressure effects of salt substitutes: } \\
\hline About $75 \%$ greater $^{5}$ & $\begin{array}{l}646.0 \\
(347.7 \text { to } 928.2) \\
\end{array}$ & $\begin{array}{l}65.0 \\
(36.0 \text { to } 95.2) \\
\end{array}$ & $\begin{array}{l}10.6 \\
(6.4 \text { to } 16.6)\end{array}$ & 1.1 (0.6 to 1.7$)$ & 635.0 (335.0 to 920.2) & 63.9 (35.0 to 94.2) & 15.1 (8.0 to 21.8$)$ \\
\hline About $100 \%$ greater $^{6}$ & $\begin{array}{l}716.2 \\
(544.9 \text { to } 892.6) \\
\end{array}$ & $\begin{array}{l}72.1 \\
(54.0 \text { to } 92.4)\end{array}$ & $\begin{array}{l}10.6 \\
(6.4 \text { to } 16.6)\end{array}$ & $1.1(0.6$ to 1.7$)$ & 706.2 (536.5 to 883.3) & 71.0 (53.1 to 91.3) & 16.8 (12.7 to 21.1$)$ \\
\hline About $180 \%$ greater ${ }^{24} \ddagger$ & $\begin{array}{l}961.4 \\
(777.3 \text { to } 1,138.4)\end{array}$ & $\begin{array}{l}97.1 \\
\text { (76.9 to } 118.2)\end{array}$ & $\begin{array}{l}10.6 \\
(6.4 \text { to } 16.6) \\
\end{array}$ & $1.1(0.6$ to 1.7$)$ & 950.9 (769.2 to $1,123.9)$ & 95.9 (75.8 to 117.2$)$ & 22.6 (18.4 to 26.8$)$ \\
\hline $\begin{array}{l}\text { Effect only in patients } \\
\text { with hypertension }\end{array}$ & $\begin{array}{l}349.7 \\
\text { (156.2 to } 534.0 \text { ) }\end{array}$ & $\begin{array}{l}34.8 \\
(15.5 \text { to } 55.0)\end{array}$ & $\begin{array}{l}10.6 \\
(6.4 \text { to } 16.6)\end{array}$ & $1.1(0.6$ to 1.7$)$ & $338.3(141.3$ to 524.8$)$ & $33.8(14.3$ to 54.0$)$ & 8.1 (3.4 to 12.5$)$ \\
\hline \multicolumn{8}{|c|}{ Dose-response relation of serum to dietary potassium intake: } \\
\hline Stronger§ & $\begin{array}{l}460.7 \\
\text { (196.3 to } 704.4)\end{array}$ & $\begin{array}{l}45.9 \\
(19.8 \text { to } 71.9) \\
\end{array}$ & $\begin{array}{l}11.9 \\
(6.9 \text { to } 19.1)\end{array}$ & $1.2(0.7$ to 1.9$)$ & 448.2 (185.3 to 695.9) & $44.6(18.6$ to 70.6$)$ & 10.7 (4.4 to 16.5$)$ \\
\hline Weakerף & $\begin{array}{l}460.7 \\
\text { (196.3 to } 704.4)\end{array}$ & $\begin{array}{l}45.9 \\
\text { (19.8 to } 71.9)\end{array}$ & $\begin{array}{l}7.5 \\
(4.7 \text { to } 11.7) \\
\end{array}$ & $0.8(0.5$ to 1.2$)$ & 452.8 (187.3 to 699.3) & 45.0 (19.1 to 71.2$)$ & $10.8(4.5$ to 16.6$)$ \\
\hline $\begin{array}{l}\text { Equal over chronic } \\
\text { kidney disease stages } \\
\text { G3a-G5 }\end{array}$ & $\begin{array}{l}460.7 \\
(196.3 \text { to } 704.4)\end{array}$ & $\begin{array}{l}45.9 \\
(19.8 \text { to } 71.9)\end{array}$ & $\begin{array}{l}5.8 \\
(3.6 \text { to } 9.0)\end{array}$ & $0.6(0.4$ to 0.9$)$ & 454.9 (190.6 to 699.5) & $45.2(19.2$ to 71.3$)$ & $10.8(4.5$ to 16.7$)$ \\
\hline
\end{tabular}

$\mathrm{SBP}=$ systolic blood pressure; $\mathrm{UI}=$ uncertainty interval; $\mathrm{CVD}=$ cardiovascular disease; $\mathrm{CKD}=$ chronic kidney disease.

*Include deaths from ischaemic heart disease, stroke (ischaemic and haemorrhagic), and other cardiovascular diseases (aortic aneurysm, hypertensive heart disease, atrial fibrillation,

cardiomyopathy, peripheral artery disease, and other cardiovascular and circulatory diseases).

tAdults aged $\geq 25$ years were considered exposed.

FHernandez et al conducted meta-analyses to evaluate the effect of salt substitutes on blood pressure and 24 hour potassium excretion. ${ }^{24}$ Estimates for excretion of potassium in 24 hours $(11.5$

$\mathrm{mmol} /$ day, $95 \%$ confidence interval 8.4 to 14.6 ) were multiplied by a factor of 1.3 to estimate the corresponding increase in potassium intake and changed the assumptions of the effects of

blood pressure and potassium intake in the sensitivity analysis.

§Increasing exponentially with decreasing kidney function.

शIncreasing linearly with decreasing kidney function.

the additional deaths increased by $12 \%$. When we assumed a linear relation or a constant response in chronic kidney disease stages G3a-G5, additional deaths decreased by $29 \%$ and $45 \%$, respectively. Altering the standard deviations of the distributions of systolic blood pressure in each group had a negligible effect on the results (data not shown). When we changed the content of potassium chloride in the salt substitute and the proportion of discretionary salt replaced by salt substitutes (eFig 5), estimates of additional deaths varied from about 600 (10\% discretionary salt replaced with salt substitutes containing $10 \%$ potassium chloride) to around 13000 additional deaths (100\% discretionary salt replaced with salt substitutes containing $25 \%$ potassium chloride). In the total population and in individuals with chronic kidney disease, the assumptions about coverage and the effects of blood pressure affected net averted deaths the most, whereas the assumptions about the dose-response relation between dietary and serum potassium had a limited effect (eFig 4). In the hypothetical worst case scenario, the highest number of estimated additional deaths were seen (about
16000; 95\% uncertainty interval 9325 to 26119), although there were substantial net averted deaths from cardiovascular disease in the total population (around 492000; 95\% uncertainty interval 208103 to 751855 ) and in those with chronic kidney disease (about $21000 ;-1187$ to 44778 ).

\section{Discussion}

Based on comparative risk assessment models, a nationwide intervention to replace normal discretionary salt with potassium enriched salt substitutes in China could prevent around 460000 deaths from cardiovascular disease, 740000 nonfatal cardiovascular events, and 8 million disability adjusted life years annually. We estimated that the intervention could prevent about one in nine deaths from cardiovascular disease in China, and that the averted deaths could greatly outweigh additional deaths related to hyperkalaemia. The intervention was also estimated to be net life saving in the subgroup of people with chronic kidney disease, with three averted deaths from a reduction in systolic blood pressure for each death related to hyperkalaemia. 


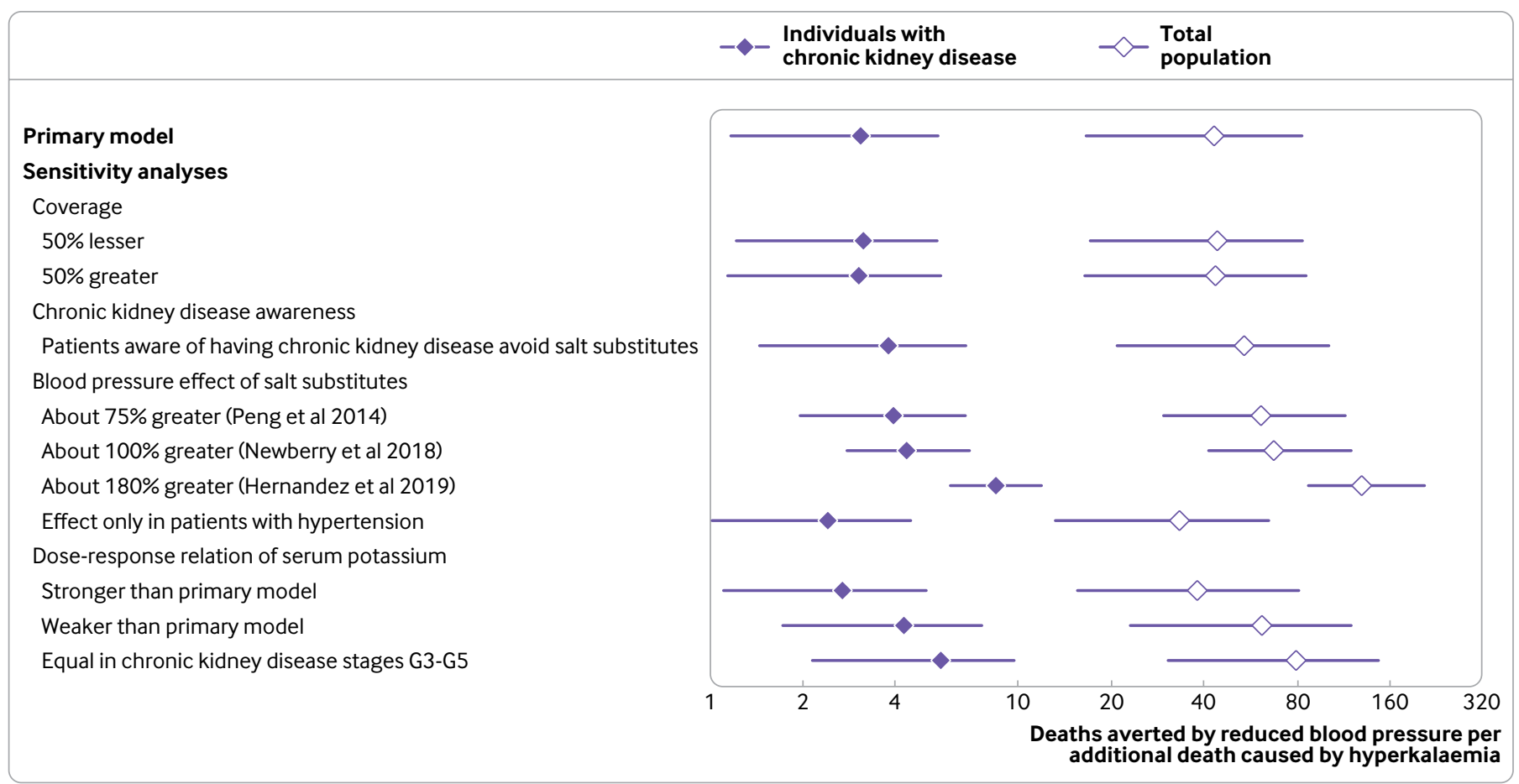

Fig 2 | Ratio of averted-to-additional deaths from cardiovascular disease in individuals with chronic kidney disease and in the total adult population in China, including individuals with chronic kidney disease, estimated by the primary model and by one way deterministic sensitivity analyses. Diamonds represent point estimates and error bars $95 \%$ uncertainty intervals. Values above one indicate net benefit (that is, greater number of deaths averted from reduction in systolic blood pressure than additional deaths from increased serum potassium). Hernandez et al conducted meta-analyses to evaluate the effect of salt substitutes on blood pressure and excretion of potassium in 24 hours. ${ }^{24}$ The estimates for excretion of potassium ( $11.5 \mathrm{mmol} / \mathrm{day}, 95 \%$ confidence interval 8.4 to 14.6$)$ were multiplied by a factor of 1.3 to estimate the corresponding increase in potassium intake and changed the assumptions of the effects of blood pressure and potassium intake in the sensitivity analysis

Policy implications

Our study has important implications. Increased systolic blood pressure is the leading cause of preventable death worldwide, ${ }^{325}$ with an especially high burden in China and similar nations where consumption of dietary sodium is high and consumption of potassium is low. ${ }^{1}$ Excess consumption of sodium is estimated to contribute to one in seven deaths from cardiovascular disease in China. ${ }^{4}$ In contrast with most Western countries where the predominant source of sodium is in pre-prepared and packaged foods, ${ }^{26}$ the major source of sodium in China is discretionary. ${ }^{1}$ Hence replacement of normal cooking and table salt with potassium enriched salt substitutes is a practical approach to reduce consumption of sodium in China. Our findings suggest that this intervention would have a large effect on the burden of cardiovascular disease in China. Although the proportion of sodium intake from processed and pre-prepared foods in China is increasing $^{1}$ and the effect of salt substitution could decline in the future, even $50 \%$ of the estimated intervention effects would constitute a large net benefit, with more than 200000 averted deaths from cardiovascular disease annually. We also recognise that a few observational studies have suggested J-shaped associations of consumption of sodium with cardiovascular disease. ${ }^{27}$ But these relations are caused by measurement errors in the estimation of consumption of sodium. ${ }^{28}$ Even if the associations were true, the studies would not be relevant to China where mean intake of sodium is much higher than any putative nadir of risk. ${ }^{27}$ Also, studies on salt substitutes ${ }^{6}$ (including the Salt Substitute and Stroke Study) showed modest reductions in dietary sodium with concomitant increases in dietary potassium, and even observational studies suggesting J-shaped associations for dietary sodium showed linearly increasing risk for the ratio of dietary sodium to potassium. ${ }^{27}$

Our model used data on reductions in systolic blood pressure from an ongoing population-wide intervention to encourage replacement of discretionary salt with potassium enriched salt substitutes in northern China. Thus our modelling implicitly incorporated important factors, such as achieved intensity, coverage, and compliance of this intervention. Because the Salt Substitute and Stroke Study is a large scale pragmatic trial, its effects are likely to reasonably approximate what a nationalscaleintervention can achieve. Evidence suggests that the palatability of salt substitutes will not be a major barrier in China, which was confirmed in the interim measurements of the Salt Substitute and Stroke Study where $98 \%$ of households randomised to the intervention used salt substitutes. ${ }^{12}$ Even if all discretionary salt was replaced with potassium enriched salt substitutes, mean intake of sodium in China would still exceed the recommendations of 
the World Health Organization. Thus promotion of salt substitutes should be (as in the Salt Substitute and Stroke Study) ${ }^{11}$ accompanied by educational campaigns to use the salt substitute more sparingly, and not more often, than standard salt. Other national government initiatives to reduce consumption of salt in the general population have succeeded when they were multifaceted and included structural activities. ${ }^{29}$ Given the increasing contribution of processed foods to consumption of sodium in China over recent years, ${ }^{1}$ an intervention that also encourages the use of salt substitutes in food reformulation, as a means of reducing sodium in processed foods, combined with substitution of discretionary salt, could further enhance the benefits to the whole population. ${ }^{30}$

The evidence suggests that salt substitutes lower systolic blood pressure, which is likely the result of reduced dietary sodium ${ }^{4}$ and increased consumption of potassium. ${ }^{20}$ The absolute magnitude of the reduction in systolic blood pressure anticipated from a nationwide salt substitute intervention is uncertain and is unlikely to be as large as that reported in the carefully controlled trials included in previous metaanalyses. ${ }^{5}$ Hence we used estimates of the effects on systolic blood pressure from a contemporary, large scale, and long term pragmatic trial in China, ${ }^{11}$ which will likely be more applicable and will more reliably estimate the effects of a national intervention in China than meta-analyses of a few smaller and less generalisable studies. The effects of salt substitution on systolic blood pressure in the Salt Substitute and Stroke Study were smaller than those reported in previous meta-analyses, suggesting that our primary results are appropriately conservative. Sensitivity analyses, which showed further reductions in the systolic blood pressure lowering effect by $50 \%$, identified substantial numbers of averted cardiovascular events and overall net benefits.

\section{Comparison with other studies}

Inconsistent results from benefit and risk assessments on the potential use of salt substitutes in European countries have been found, likely related to differences in methodology. ${ }^{31-33}$ In two studies, consumption of potassium in the Netherlands ${ }^{32}$ and Norway ${ }^{33}$ after nationwide salt substitution was predicted and compared with dietary guidelines and putative safety levels. In another study, the incidence of life threatening hyperkalaemia caused by a hypothesised salt substitution in the UK was predicted. None of these assessments, however, estimated the effects on blood pressure and cardiovascular disease. The benefits of strategies to reduce sodium (including salt substitutes) on cardiovascular disease in China have been modelled, ${ }^{38}$ but potential risks were not estimated and the evaluation did not provide estimates for important subgroups, such as those with chronic kidney disease. Our findings extend previous studies by quantifying the potential net effects (benefits and harms) from a nationwide salt substitution intervention.
Concerns about the potential harms of potassium enriched salt substitutes in chronic kidney disease are largely based on case reports, which mostly describe non-fatal events in people consuming salt substitutes with a high content $(>40 \%)$ of potassium chloride. We identified only one report of a fatal event; a middle aged man died after a suspected suicide by consuming a large amount (21 g) of salt substitute (53\% potassium), leading to severe hyperkalaemia and cardiac arrest. ${ }^{39}$ Only limited evidence, therefore, links increased consumption of potassium from salt substitutes and the risk of hyperkalaemia. Nevertheless, we modelled potential harms of potassium enriched salt substitutes in individuals with chronic kidney disease to conservatively estimate the net effect of salt substitutes. All findings, including sensitivity analyses that assumed a greater doseresponse between dietary and serum potassium, suggested net cardiovascular benefits of potassium based salt substitution in individuals with chronic kidney disease. Given these estimated benefits, strategies to mitigate the risk of hyperkalaemia by encouraging individuals with chronic kidney disease to avoid salt substitutes in a national intervention could result in net harm (because of missed cardiovascular disease benefits) in this subpopulation. Our results suggest that alternative strategies should be evaluated to minimise the risk in the population but retain the benefits, such as increased screening for chronic kidney disease and enhanced monitoring of serum concentrations of potassium in patients, especially in those with advanced disease where the risk is greatest.

Other interventions for chronic diseases also have adverse effects but a favourable net benefit. For example, a common serious side effect of drugs that block the renin-angiotensin-aldosterone system is angioedema, which occurred in $0.68 \%$ of patients receiving enalapril. ${ }^{34}$ Metformin, a widely used glucose lowering agent, can cause fatal lactic acidosis (1.1-3.9 deaths per 100000 patient years), especially in patients with advanced chronic kidney disease. ${ }^{35}$ In comparison, the risk of salt substitutes, estimated by the primary model and in sensitivity analyses, was 0.61.5 deaths per 100000 people exposed.

\section{Limitations of this study}

Our investigation has potential limitations. The estimated effect of the intervention on systolic blood pressure was based on a study that recruited individuals with prevalent stroke or hypertension and might not be generalisable to the whole Chinese population. Net benefits did not change greatly in sensitivity analyses, however, when we excluded any health benefits in people with normal blood pressure or assumed a 50\% lower effect on systolic blood pressure. We did not evaluate the cost effectiveness or the national feasibility of our modelled nationwide salt substitution intervention. We did not explicitly evaluate alternative policies (eg, partial price subsidy funded by the government), which could have an effect on the use of salt substitutes. ${ }^{36}$ Estimates from 
our sensitivity analysis assuming $50 \%$ of the salt substitute use and systolic blood pressure effect of the Salt Substitute and Stroke Study, however, suggested substantial net benefits overall and in those with chronic kidney disease.

Although providing salt substitutes free of charge is a possible approach to reduce medical costs related to cardiovascular disease, more studies are needed to investigate which combination of intervention strategies might be preferable to policy makers in China. We did not consider the additional benefits of partial salt substitution on non-cardiovascular outcomes, such as stomach cancer, which is prevalent in parts of China, or pre-eclampsia in pregnant women, which might lead to underestimation of the net benefits of the intervention. Future studies should evaluate the benefits of potassium enriched salt substitutes in specific subpopulations, such as pregnant women, and for the prevention of non-cardiovascular disease outcomes.

Evidence to confirm the dose-response relation between dietary and serum potassium in patients with chronic kidney disease is limited, and is not from Asian populations, and we incorporated the uncertainty in these estimates into all analyses. Our sensitivity analyses identified only a modest impact of changing the dose-response assumptions, with central estimates of additional deaths from cardiovascular disease ranging from 5403 (assuming similar responses between dietary and serum potassium in chronic kidney disease stages G3a-G5) to 11893 (assuming an exponential increase in responses between dietary and serum potassium with reduced kidney function). We did not incorporate any potential benefits of increased consumption of potassium for individuals with hypokalaemia. Estimates of cardiovascular disease burden before the intervention were based on the Global Burden of Disease Study, and although the methodology behind these estimates is continuously improving, estimations of rare diseases and non-fatal outcomes might be less accurate. ${ }^{13-15}$ Although most of our data on China were from 2015, data on the prevalence of chronic kidney disease were for 2009-10 and might have modestly changed since that time. ${ }^{217}$ The reduction in systolic blood pressure from salt substitutes, however, could eventually decrease the prevalence of chronic kidney disease by reducing the annual number of new cases of chronic kidney disease by almost $7 \%$.

Comparative risk assessment models provide a simple tool to simultaneously model multiple disease processes and risk factors. The disadvantages compared with more complex model approaches, however, include the lack of an explicit time component, failure to allow for recurring events, and inability to model interactions between individuals, populations, or their environment. ${ }^{37}$ Our modelling study does not prove that a national intervention to encourage potassium enriched salt substitutes will prevent cardiovascular disease; rather, it provides important quantitative estimates, corresponding uncertainty, and assessments of the sensitivity of the findings to different inputs to guide the design, implementation, and evaluation of an appropriate intervention in a national population.

\section{Strengths of this study}

Our study has several strengths. Data were derived, whenever possible, from nationally representative sources, increasing the validity and generalisability of the results. Because obtaining valid estimates of sodium intake are challenging in large populations, we did not rely on estimated intakes of salt or sodium in our primary model. Instead, we used the effects on systolic blood pressure of the intervention from the Salt Substitute and Stroke Study, an ongoing large scale (>20000 participants) potassium enriched salt substitute intervention that shows that these interventions are feasible at a scale in China, with clinically meaningful effects on blood pressure. ${ }^{12}$ Cardiovascular benefits of lower systolic blood pressure were derived from pooled analyses of large prospective studies with further accounting for age specific effects. Clinical trial data were used to estimate the dose-response relation between dietary and serum potassium in individuals with chronic kidney disease. Data on risk of cardiovascular death and serum concentrations of potassium in individuals with chronic kidney disease, and data on the risk of cardiovascular disease by serum concentrations of potassium, were from pooled analyses of multiple prospective cohorts. We used comparative risk models to estimate benefits, risks, and the net effects, jointly incorporating the uncertainties of all inputs. We conducted a suite of additional sensitivity analyses to assess the influence of varying model inputs and assumptions, supporting the robustness of the findings.

\section{Conclusions}

A nationwide intervention to encourage the use of potassium enriched salt substitutes was estimated to substantially reduce deaths from cardiovascular disease, non-fatal cardiovascular events, and disability adjusted life years in China, with the benefits outweighing the harms in the overall population and in individuals with chronic kidney disease. Our results suggest that a person in the general population and an individual with chronic kidney disease would be more likely to survive with the intervention than without. Although our estimates can provide guidance to policy makers, large clinical studies (such as the ongoing Salt Substitute and Stroke Study) are needed to evaluate the potential benefits versus harms of salt substitution.

\section{AUTHOR AFFILIATIONS}

${ }^{1}$ George Institute for Global Health, Faculty of Medicine, University of New South Wales, Sydney, PO Box M201, Missenden Road, NSW 2050, Australia

${ }^{2}$ Friedman School of Nutrition Science and Policy at Tufts University, Boston, MA, USA

${ }^{3}$ Johns Hopkins Bloomberg School of Public Health, Baltimore, MD, USA

${ }^{4}$ Johns Hopkins University School of Medicine, Baltimore, MD, USA

${ }^{5}$ George Institute for Global Health at Peking University Health

Science Centre, Beijing, China 
${ }^{6}$ Resolve to Save Lives, New York City, NY, USA

${ }^{7}$ Imperial College London, London, UK

Contributors: LJA, DM, and JHYW are joint senior authors. KM, LH, $B N$, and LJA provided unpublished data for analysis. MM, GS, RG, LJA, DM, and JHYW conceived the study. MM undertook the analysis unde the supervision of GS, FC, and DM. MM, LJA, and JHYW wrote the first draft. All authors interpreted data, contributed to critical revisions, and approved the final version of the article. MM is the guarantor. The corresponding author attests that all listed authors meet authorship criteria and that no others meeting the criteria have been omitted.

Funding: LH, MM, BN, and JHYW are researchers within a National Health and Medical Research Council Centre for Research Excellence in reducing salt intake using food policy interventions (APP1117300). JHYW is supported by a UNSW Scientia Fellowship. The analysis was conducted on behalf of Resolve to Save Lives, an initiative of Vital Strategies. Resolve to Save Lives is funded by grants from Bloomberg Philanthropies; the Bill and Melinda Gates Foundation; and Gates Philanthropy Partners, which is funded with support from the Chan Zuckerberg Foundation. The funders had no role in study design, data collection, data analysis, data interpretation, or writing of the report.

Competing interests: All authors have completed the ICMJE uniform disclosure form at www.icmje.org/coi_disclosure.pdf and declare: support from Bloomberg Philanthropies, the Bill and Melinda Gates Foundation, Gates Philanthropy Partners, and the Chan Zuckerberg Foundation for the submitted work; LH, MM, BN, and JHYW report research funding from the National Health and Medical Research Council, and JHYW reports research funding from UNSW. MT, BN, JHYW, and $\mathrm{LH}$ report provision of salt substitute for research trials by Beijing Salt Manufacturing, Jiangsu Sinokone Technology, and NuTek. RG reports research grants from the National Institutes of Health, outside the present work. KM reports grants and personal fees from Kyowa Kirin and personal fees from Akebia, outside the submitted work. RM reports research grants from the National Institutes of Health (NIH) and Bill and Melinda Gates Foundation, Nestle, and Danone; and personal fees from Bunge and Development Initiatives; all outside the present work. LJA reports research grants from NIH and honorariums from UpToDate, outside the present work. DM reports research funding from NIH and the Bill and Melinda Gates Foundation; personal fees from GOED, Danone, Motif FoodWorks, Nutrition Impact, Pollock Communications, Bunge, Indigo Agriculture, Amarin, Acasti Pharma, Cleveland Clinic Foundation, and America’s Test Kitchen; scientific advisory board, Elysium Health (with stock options), Omada Health and DayTwo; and chapter royalties from UpToDate; all outside the submitted work.

Ethical approval: Not required.

Data sharing: The data on cardiovascular events are available for download from the Global Burden of Disease Result Tools at http:/ ghdx.healthdata.org/gbd-results-tool. The data on blood pressure levels are available for download from the Global Burden of Diseases Study at http://ghdx.healthdata.org/record/global-burden-diseasestudy-2015-gbd-2015-hypertension-and-systolic-blood-pressureleast-110. No additional data available.

The lead author (MM) affirms that the manuscript is an honest, accurate, and transparent account of the study being reported; that no important aspects of the study have been omitted; and that any discrepancies from the study as planned have been explained.

Dissemination to related patient and public communities: We plan to issue a press release on official publication of this manuscript and disseminate our findings through social media outlets, in order for the results of the study to have a broad public outreach. We are keenly interested in the perceptions of our results among patients with kidney disease and their providers. To this end, we will engage these communities through presentations at relevant lay and scientific meetings and other venues.

This is an Open Access article distributed in accordance with the Creative Commons Attribution Non Commercial (CC BY-NC 4.0) license, which permits others to distribute, remix, adapt, build upon this work non-commercially, and license their derivative works on different terms, provided the original work is properly cited and the use is noncommercial. See: http://creativecommons.org/licenses/by-nc/4.0/.

1 Du S, Wang H, Zhang B, Popkin BM. Dietary potassium intake remains low and sodium intake remains high, and most sodium is derived from home food preparation for Chinese adults, 1991-2015 trends. J Nutr 2020:nxz332. doi:10.1093/jn/nxz332

2 Lu J, Lu Y, Wang $X$, et al. Prevalence, awareness, treatment, and control of hypertension in China: data from 1.7 million adults in a population-based screening study (China PEACE Million Persons
Project). Lancet 2017;390:2549-58. doi:10.1016/S01406736(17)32478-9

3 Forouzanfar MH, Liu P, Roth GA, et al. Global burden of hypertension and systolic blood pressure of at least 110 to $115 \mathrm{~mm} \mathrm{Hg}, 1990$ 2015. JAMA 2017;317:165-82. doi:10.1001/jama.2016.19043

4 Mozaffarian D, Fahimi S, Singh GM, et al, Global Burden of Diseases Nutrition and Chronic Diseases Expert Group. Global sodium consumption and death from cardiovascular causes. N Engl J Med 2014:371:624-34. doi:10.1056/NEIMoa1304127

5 Peng Y-G, Li W, Wen X-X, Li Y, Hu JH, Zhao LC. Effects of salt substitutes on blood pressure: a meta-analysis of randomized controlled trials. Am / Clin Nutr 2014;100:1448-54. doi:10.3945/ajcn.114.089235

6 Newberry SJCM, Anderson C, Fu W, et al. Effects of dietary sodium and potassium intake on chronic disease outcomes and related risk factors. Systematic Review No 206. (Prepared by the Southern California Evidence-based Practice Center under Contract No 290 2015-00010-I.) Agency for Healthcare Research and Quality, 2018.

7 Chang HY, Hu YW, Yue CS, et al. Effect of potassium-enriched salt on cardiovascular mortality and medical expenses of elderly men. Am J Clin Nutr 2006;83:1289-96. doi:10.1093/ajcn/83.6.1289

8 Kovesdy CP, Matsushita K, Sang Y, et al, CKD Prognosis Consortium. Serum potassium and adverse outcomes across the range of kidney function: a CKD Prognosis Consortium meta-analysis. Eur Heart / 2018;39:1535-42. doi:10.1093/eurheartj/ehy100

9 Kidney Disease Outcomes Quality Initiative (K/DOQI). K/DOQI clinical practice guidelines on hypertension and antihypertensive agents in chronic kidney disease. Am J Kidney Dis 2004;43(Suppl 1):S1-290.

10 Wang F, Zhang L, Wang H, China National Survey of CKD Working Group. Awareness of CKD in China: a national cross-sectional survey. Am J Kidney Dis 2014;63:1068-70. doi:10.1053/j. ajkd.2014.01.012

11 Neal B, Tian M, Li N, et al. Rationale, design, and baseline characteristics of the Salt Substitute and Stroke Study (SSaSS)-A large-scale cluster randomized controlled trial. Am Heart J 2017;188:109-17. doi:10.1016/j.ahj.2017.02.033

12 Huang L, Tian M, Yu J, et al. Interim effects of salt substitution on urinary electrolytes and blood pressure in the China Salt Substitute and Stroke Study (SSaSS). Am Heart J 2020;221:136-45. doi:10.1016/j.ahj.2019.12.020

13 Kyu HH, Abate D, Abate KH, et al, GBD 2017 DALYs and HALE Collaborators. Global, regional, and national disability-adjusted life-years (DALYS) for 359 diseases and injuries and healthy life expectancy (HALE) for 195 countries and territories, 1990-2017: a systematic analysis for the Global Burden of Disease Study 2017. Lancet 2018;392:1859-922. doi:10.1016/S01406736(18)32335-3

14 James SL, Abate D, Abate KH, et al, GBD 2017 Disease and Injury Incidence and Prevalence Collaborators. Global, regional, and national incidence, prevalence, and years lived with disability for 354 diseases and injuries for 195 countries and territories, 1990-2017: a systematic analysis for the Global Burden of Disease Study 2017. Lancet 2018;392:1789-858. doi:10.1016/S01406736(18)32279-7

15 Roth GA, Abate D, Abate KH, et al, GBD 2017 Causes of Death Collaborators. Global, regional, and national age-sex-specific mortality for 282 causes of death in 195 countries and territories, 1980-2017: a systematic analysis for the Global Burden of Disease Study 2017. Lancet 2018;392:1736-88. doi:10.1016/S01406736(18)32203-7

16 Lacey B, Lewington S, Clarke R, et al, China Kadoorie Biobank collaborative group. Age-specific association between blood pressure and vascular and non-vascular chronic diseases in 0.5 million adults in China: a prospective cohort study. Lancet Glob Health 2018;6:e641-9. doi:10.1016/S2214-109X(18)30217-1

17 Zhang L, Wang F, Wang L, et al. Prevalence of chronic kidney disease in China: a cross-sectional survey. Lancet 2012;379:815-22. doi:10.1016/S0140-6736(12)60033-6

18 Hallan SI, Matsushita K, Sang Y, et al, Chronic Kidney Disease Prognosis Consortium. Age and association of kidney measures with mortality and end-stage renal disease. JAMA 2012;308:2349-60. doi:10.1001/jama.2012.16817

19 Matsushita K, Mahmoodi BK, Woodward M, et al, Chronic Kidney Disease Prognosis Consortium. Comparison of risk prediction using the CKD-EPI equation and the MDRD study equation for estimated glomerular filtration rate. JAMA 2012;307:1941-51. doi:10.1001/ jama.2012.3954

20 Aburto NJ, Hanson S, Gutierrez H, Hooper L, Elliott P, Cappuccio FP. Effect of increased potassium intake on cardiovascular risk factors and disease: systematic review and meta-analyses. BM/ 2013:346:f1378. doi:10.1136/bmj.f1378

21 Palmer BF. Regulation of potassium homeostasis. Clin J Am Soc Nephrol 2015;10:1050-60. doi:10.2215/CJN.08580813

22 Kovesdy CP, Appel LI, Grams ME, et al. Potassium Homeostasis in Health and Disease: A Scientific Workshop Cosponsored by the National Kidney Foundation and the American Society of 
Hypertension. Am J Kidney Dis 2017;70:844-58. doi:10.1053/j. ajkd.2017.09.003

23 Singh GM, Danaei G, Farzadfar F, et al, Global Burden of Metabolic Risk Factors of Chronic Diseases Collaborating Group; Asia-Pacific Cohort Studies Collaboration (APCSC), Diabetes Epidemiology: Collaborative analysis of Diagnostic criteria in Europe (DECODE), Emerging Risk Factor Collaboration (ERFC), Prospective Studies Collaboration (PSC). The age-specific quantitative effects of metabolic risk factors on cardiovascular diseases and diabetes: a pooled analysis. PLoS One 2013;8:e65174. doi:10.1371/journal. pone.0065174

24 Hernandez AV, Emonds EE, Chen BA, et al. Effect of low-sodium salt substitutes on blood pressure, detected hypertension, stroke and mortality: A systematic review and meta-analysis of randomised controlled trials. Heart 2019;105:953-60.

25 Lim SS, Vos T, Flaxman AD, et al. A comparative risk assessment of burden of disease and injury attributable to 67 risk factors and risk factor clusters in 21 regions, 1990-2010: a systematic analysis for the Global Burden of Disease Study 2010 [corrections in Lancet 2013;381:1276 and 2013;381:628]. Lancet 2012;380:2224-60. doi:10.1016/S0140-6736(12)61766-8

26 Bhat S, Marklund M, Henry ME, et al. A systematic review of the sources of dietary salt around the world. Adv Nutr 2020:nmz134. doi:10.1093/advances/nmz134

27 Mente A, O’Donnell M, Rangarajan S, et al. Urinary sodium excretion, blood pressure, cardiovascular disease, and mortality: a community-level prospective epidemiological cohort study. Lancet 2018;392:496-506. doi:10.1016/S0140-6736(18)31376-X

$28 \mathrm{He} \mathrm{FJ}$, Campbell NRC, Ma Y, MacGregor GA, Cogswell ME, Cook NR. Errors in estimating usual sodium intake by the Kawasaki formula alter its relationship with mortality: implications for public health. Int J Epidemiol 2018;47:1784-95. doi:10.1093/ije/dyy114

29 McLaren L, Sumar N, Barberio AM, et al. Population-level interventions in government jurisdictions for dietary sodium reduction. Cochrane Database Syst Rev 2016;9:CD010166. doi:10.1002/14651858.CD010166.pub2
30 He FJ, Pombo-Rodrigues S, Macgregor GA. Salt reduction in England from 2003 to 2011: its relationship to blood pressure, stroke and ischaemic heart disease mortality. BMJ Open 2014;4:e004549. doi:10.1136/bmjopen-2013-004549

31 Committee on Toxicity of Chemicals in Food, Consumer Products and the Environment Statement on potassium-based replacements for sodium chloride and sodium-based additives. Food Standards Agency; 2017. https://cot.food.gov.uk/sites/default/files/potassiumstatement.pdf.

32 van Buren L, Dötsch-Klerk M. Seewi G, Newson RS. Dietary impact of adding potassium chloride to foods as a sodium reduction technique. Nutrients 2016;8:235. doi:10.3390/nu8040235

33 Steffensen I-L, Frølich W, Dahl KH, et al. Benefit and risk assessment of increasing potassium intake by replacement of sodium chloride with potassium chloride in industrial food products in Norway. Food Chem Toxicol 2018;111:329-40. doi:10.1016/j.fct.2017.11.044

34 Kostis JB, Kim HJ, Rusnak J, et al. Incidence and characteristics of angioedema associated with enalapril. Arch Intern Med 2005;165:1637-42. doi:10.1001/archinte.165.14.1637

35 Howlett HC, Bailey Cl. A risk-benefit assessment of metformin in type 2 diabetes mellitus. Drug Saf 1999:20:489-503. doi:10.2165/00002018-199920060-00003

36 Li N, Yan LL, Niu W, et al. The effects of a community-based sodium reduction program in rural china - a cluster-randomized trial. PLoS One 2016;11:e0166620. doi:10.1371/journal.pone.0166620

37 Briggs ADM, Wolstenholme J, Blakely T, Scarborough P. Choosing an epidemiological model structure for the economic evaluation of non-communicable disease public health interventions. Popul Health Metr 2016;14:17. doi:10.1186/s12963-016-0085-1

38 Wang M, Moran AE, Liu J, et al. Projected impact of salt restriction on prevention of cardiovascular disease in China: a modeling study. PLoS One 2016;11:e0146820. doi:10.1371/journal.pone.0146820

39 Restuccio A. Fatal hyperkalemia from a salt substitute. Am J Emerg Med 1992. doi:10:171-73. 10.1016/0735

Web appendix: Appendix 